


\title{
Enhancing the Social Networks of People with Mental IIInesses: A Qualitative Study on the Role of Peer-Operated Recovery Learning Communities
}

\author{
Jonathan Delman, PhD, JD, Kathleen Biebel, PhD, \& Shums Alikhan, BS
}

\begin{abstract}
Social Integration is a process through which an individual establishes and maintains meaningful interpersonal relationships characterized by mutual exchange with community members in nonclinical settings.
\end{abstract}

$\mathrm{S}$ distress, fewer psychiatric hospitalizations, and improved self-confidence. ${ }^{1}$ Yet, people with SMI often have difficulty building and maintaining social connections, and there is no established best practice for helping individuals with SMI socially integrate. ${ }^{2}$ In fact, the social networks of people with SMI, in comparison to those of people without disabilities, are smaller, less satisfactory, and more likely to be made up mostly of relatives and other mental health consumers. ${ }^{3}$

"Social integration" involves a process through which an individual establishes and maintains meaningful interpersonal relationships characterized by mutual exchanges with community members in nonclinical settings. The research on how people with SMI (re)integrate socially is sparse and lacking a conceptual framework. ${ }^{4}$ Peer-operated programs, which are administratively and financially controlled and staffed by people with lived experience of mental illness, have shown some promise in helping people with SMI build or rebuild their social networks. ${ }^{5,6,7}$

Massachusetts-based Recovery Learning Communities (RLCs) are peer-run programs that offer safe and supportive environments for individuals with SMI to develop, practice, and solidify social relationships. ${ }^{8,2}$ Some of the opportunities that RLCs offer are: peer support groups, wellness classes, education, employment supports, computer lab and library access, as well as community meetings. Engagement in peer support activities allows participants to create relationships and practice a new identity (rather than that of a "mental patient"), leading to improved coping skills, social functioning, and quality of life. ${ }^{8}$

In 2014, researchers from the UMass Systems and Psychosocial Advances Research Center (SPARC) partnered with the Central Massachusetts RLC to complete a pilot study exploring the relationship between RLC participation and experiences of social integration. Utilizing participatory action research (PAR) principles, investigators from both SPARC and the RLC worked collaboratively to design an exploratory qualitative study, analyze data, and present findings.

A qualitative interview guide, grounded in a conceptual framework examined the impact of various aspects of the RLC on the psychosocial life of participants. ${ }^{2}$ Investigators interviewed ten RLC participants for this pilot study. Participants RLC attendance varied from 1 to 4 times a week for anywhere from 4 months to as long as 4 years.

In addition, investigators held a focus group with RLC staff members, who are also persons with lived mental health experience. A modified grounded theory approach was used to code and analyze the data. Two investigators engaged in comparative analysis to identify key themes.

Twelve themes regarding RLC impact on social integration emerged. The identified themes fall into one of two domains: 1) RLC Attributes and 2) Psychosocial Outcomes. Each domain was organized into two categories. The RLC Attributes categories are Atmosphere and Opportunities, while the Psychosocial Outcomes categories are Intrapersonal and Interpersonal. 


\section{RLC Attributes: What is it about the RLCs that help participants become more socially active?}

\section{Atmosphere:}

- Judgment-free: Having been diagnosed and otherwise "judged" in other treatment and social settings, RLC participants were pleased that staff and peers at the RLC saw them as people first, and not as cases or illnesses;

- Flexible: RLC participation is completely voluntary and participants can choose whatever meetings and activities they wish to engage in; and

- Relaxed/open: RLC peers and staff share concerns, emotional support, and coping strategies that promote personal and social well-being.

\section{Opportunities:}

- Leadership: RLC participants are provided opportunities to facilitate peer groups and trainings and to organize social and advocacy activities;

- Meeting peers: Many new RLC participants are isolated and have a poor self-image. RLCs offer new opportunities to meet peers and people in the larger community; and

- Trainings and workshops: RLC participants can choose to attend appealing groups, classes and trainings that assist in personal recovery and/or encourage social interaction.

\section{Psychosocial Outcomes: How do the social lives of RLC participants' change with RLC participation?}

\section{Intrapersonal Outcomes:}

- Positive identity transformation: Participants begin to see themselves as capable of working and socializing;

- Increased self-esteem: Many participants observe for the first time that recovery is possible and they become more optimistic and hopeful;
- Increased sense of responsibility: Participants begin to pursue jobs and (re)build family relationships; and

- Improved coping skills: Participants develop wellness management plans and reduce stress; many use hospitals and emergency rooms less frequently.

\section{Interpersonal Outcomes:}

- Enhanced social networks and activities: Participants often make numerous friends through RLC activities or other outside social events. As a participant's social skills increase and their social anxiety lessens, they begin to build relationships outside of the RLC community; and

- Holding jobs and other positions of responsibility: Participants develop new skills, gain the confidence to seek employment, and become more resilient, allowing for longer periods of employment.

Our small convenience sample, all of whom participated in the activities of a single RLC, suggests caution in making inferences to other populations. The framework for social integration of people with SMI should be further developed through additional qualitative studies with a larger and more representative group of RLCs and people with SMI. These and other data could be used to develop structure, process and outcome measures of social integration through further study, perhaps using a participatory action research approach. When measures are developed or adapted, longitudinal studies could assess relative effectiveness of RLCs.

The atmosphere at the RLCs allows for the creation of opportunities that permit individuals with mental illnesses to develop an improved sense of self, make friends, and build stronger social networks. As part of their quality improvement strategy, RLCs should regularly assess the continuing presence of their key attributes that support this atmosphere and opportunities. Additionally, these key attributes should be seriously considered by other programs wanting to promote social integration for people with SMI.

To learn more about RLCs please visit the MA DMH website:

http://www.mass.gov/eohhs/consumer/behavioral-health/mental-health/recovery-learning-communities.html

Research Team: Jonathan Delman, PhD, JD (Principal Investigator); Kathleen Biebel, PhD (Principal Investigator); Shums Alikhan, BS; Funders: NIH, CCTS; Time Frame: 2014-2015; Contact: Jonathan.Delman@umassmed.edu 


\section{References}

1. Kogstad, R. E., Mönness, E., \& Sörensen, T. (2013). Social networks for mental health clients: Resources and solution. Community Mental Health Journal, 49(1), 95-100.

2. Delman, J., Delman, D. R., Vezina, B. R., \& Piselli, J. (2014). Peer led Recovery Learning Communities: Expanding social integration opportunities for people with lived experience of psychiatric disability and emotional distress. Global Journal of Community Psychology Practice, 5(1), 1-11. Retrieved from http://www.gjcpp.org/pdfs/2014-SI11-20140519.pdf

3. McCorkle, B. H., Rogers, E. S., Dunn, E. C., Lyass, A., \& Wan, Y. M. (2008). Increasing social support for individuals with serious mental illness: Evaluating the compeer model of intentional friendship. Community Mental Health Journal, 44(5), 359-366. doi: 10.1007/s10597-008-9137-8

4. Wong, Y. I., Matejkowski, J., \& Lee, S. (2011). Social integration of people with serious mental illness: Network transactions and satisfaction. The Journal of Behavioral Health Services \& Research, 38(1), 51-67. doi: 10.1007/s11414009-9203-1

5. Brown, L. D. (2009). How people can benefit from mental health consumer-run organizations. American Journal of Community Psychology, 43(3-4), 177-188. doi: 10.1007/s10464-009-9233-0

6. Nelson, G., Ochocka, J., Janzen, R., \& Trainor, J. (2006). A longitudinal study of mental health consumer/survivor initiatives: Part 1-literature review and overview of the study. Journal of Community Psychology, 34(3), 247-260. doi: 10.1002/jcop.20097

7. Schutt, R. K., \& Rogers, E. S. (2009). Empowerment and peer support: Structure and process of self-help in a consumer-run center for individuals with mental illness. Journal of Community Psychology, 37(6), 697- 710. doi: $10.1002 /$ jcop. 20325

8. Ahmed, A. O., Doane, N. J., Alex Mabe, P., Buckley, P. F., Birgenheir, D., \& Goodrum, N. M. (2012). Peers and peerled interventions for people with schizophrenia. Psychiatric Clinics of North America, 35(3), 699-715. doi: 10.1016/j. psc.2012.06.009 